\title{
DEMOCRACIA PARTICIPATIVA, DELIBERAÇÃO E CIDADANIA: DA GRÉCIA AOS NOSSOS DIAS
}

\author{
José Marcos Miné Vanzella ${ }^{1}$ \\ Gabriel Alves da Silva Júnior ${ }^{2}$
}

\begin{abstract}
Resumo: Este ensaio, com metodologia histórica-teórico conceitual, aborda a evolução da democracia, a partir da identificação de seus elementos essenciais na ampliação da participação e no desenvolvimento da deliberação. Parte-se da democracia direta surgida na Grécia passando pela democracia indireta representativa moderna, a qual viabiliza a passagem para o Estado nação. Apresenta o esvaziamento da cidadania pela representação moderna, bem como sua recuperação pelo desenvolvimento da democracia participativa e deliberativa, as quais concretizam princípios da cidadania e dignidade da pessoa humana, através da promoção de maior participação de todos, racionalidade, e controle social das instituições.
\end{abstract}

Palavras-chave: Democracia Participativa. Democracia Deliberativa. História. Cidadania. Direitos Humanos.

\section{PARTICIPATORY DEMOCRACY, DELIBERATION AND CITIZENSHIP: FROM GREECE TO OUR DAYS}

\begin{abstract}
This essay, with historical-theoretical-conceptual methodology, approaches the evolution of democracy, from the identification of its essential elements in the expansion of participation and in the development of deliberation. It starts from the direct democracy that emerged in Greece, passing through the modern representative indirect democracy, which facilitates the transition to the nation state. It presents the emptying of citizenship by modern representation, as well as its recovery by the development of participatory and deliberative democracy, which concretizes principles of citizenship and dignity of the human person, through the promotion of greater participation of all, rationality, and social control of institutions.
\end{abstract}

Key-words: Democracy Participatory. Deliberative Democracy. History. Ctizenship. Human Rights.

\footnotetext{
${ }^{1}$ Doutor em Filosofia pela Universidade Gama Filho (Rio de Janeiro) Professor e Pesquisador no Programa de Mestrado em Direito do Centro Unisal - U.E. Lorena (SP) E-Mail: enimine@ gmail.com

2 Advogado e Aluno no Programa de Mestrado em Direito do Centro Universitário Salesiano de São PauloUnidade Educacional de Lorena (SP) E-mail: advbiel@gmail.com
} 


\section{INTRODUÇÃO}

O presente ensaio procura compreender a partir de um metodologia histórica-teóricoconceitual, quais os elementos principais da evolução conceitual histórica da democracia da Grécia aos nossos dias. Seu objetivo é contribuir com a compreensão, valorização e análise da proposta de democracia participativa e deliberativa, prevenindo quanto a possíveis retrocessos cognitivos, políticos e sociais.

Essa abordagem justifica-se em nosso contexto de crise que coloca a necessidade de busca de alternativas capazes de fazer frente a corrupção e as coerções funcionais dos subsistemas, econômico e político. Para tanto pretende alojar-se no grupo de trabalho “TEORIAS DA DEMOCRACIA E DIREITOS POLÍTICOS” por abordar o sentido conceitual da ampliação das formas de participação política e do desenvolvimento de nossa cultura cívica.

Investiga-se as seguintes questões, que correspondem aos itens deste ensaio: quais as características conceituais originárias da democracia e da cidadania na Grécia; quais os traços conceituais da democracia moderna; como a democracia moderna se relaciona com a cidadania e em que sentido se desenvolve os atuais conceitos de democracia deliberativa e participativa.

Pretende-se com a abordagem da história conceitual da democracia através da análise do modelo atual vigente no País, uma vez que a crise institucional da democracia representativa justifica a necessidade de repensá-la para compreender seus elementos essenciais e verificar a possibilidade de uma proposta mais ampla.

\section{O CONCEITO DE DEMOCRACIA NA GRÉCIA}

Segundo Paulo Bonavides em sua obra Ciência Política (2014, p.288), a democracia surgiu historicamente na Grécia antiga através das reformas implementadas inicialmente por Clístenes no século VI a.C. e concluídas por Péricles no século V a.C., onde o povo reunido numa praça denominada agorá, onde se realizava os debates e as tomadas de decisões no exercício do poder político de forma direta e imediata originando a democracia direta.

Para o Jurista Alberto Antonio Zvirblis (2006, p. 48-49), a democracia direta se constituía na participação dos membros na deliberação direta do governo, sem qualquer intermediação de representantes. A possibilidade de tal prática decorria do tamanho reduzido das cidades sem grande população. Assim, a polis, cuja definição grega de cidade, apresentava três divisões de classe: os cidadãos denominados eupátridas, com a prerrogativa de participar 
na vida política; os metecos, os estrangeiros que embora fossem livres não podiam participar da vida pública, como também as mulheres e finalmente, os escravos que tinham a incumbência da realização dos trabalhos manuais e o cidadão devia ocupar-se exclusivamente com os serviços públicos da cidade, abdicando da maior parte do tempo, dos seus trabalhos pessoais e de sua vida doméstica.

Segundo Bonavides (2014 p. 289), autores mais rigorosos asseveram que não houve na Grécia democracia verdadeira, mas uma aristocracia democrática, o que evidentemente traduz um paradoxo. Ou democracia minoritária, reproduzindo o pensamento de Hegel, quanto ao progresso qualitativo e quantitativo da civilização clássica, tocante á conquista da liberdade humana, onde para este filósofo, o Oriente prevalecia a liberdade de um só, para a Grécia e Roma, a liberdade de alguns, e o mundo germânico, ou seja, o mundo moderno, a liberdade de todos, como quer Francesco Nitti em sua obra La Demócratie, (1933, p.11).

Ainda Bonavides (2014, p. 289), as condições para o funcionamento do sistema de democracia direta no Estado-cidade da Grécia consistiam em primeiro lugar, a base social escrava, que permitia ao homem livre ocupar-se somente dos negócios públicos, numa militância rude, exaustiva, permanente, diuturna. Nenhuma preocupação de ordem material atormentava o cidadão na antiga Grécia, correspondendo o homem econômico atuais ao homem político da antiguidade com qual a liberdade do cidadão substituía a liberdade do homem.

Em segundo lugar, outra condição social compelia o cidadão grego a conservar permanentemente o interesse para preservar a democracia e a valorar a participação soberana com sua vontade para moldar a vida pública, a vida da cidade.

Esta valoração consistia no quanto a democracia oferecia ao bem que o cidadão almejava receber e o que efetivamente recebia do Estado prevalecendo tal condicionante para toda sua existência.

Para Zvirblis (2006, p. 51), o conceito de democracia não pode ser absoluto, porque o povo da Grécia antiga não é o mesmo povão da atualidade.

A própria concepção de comunidade é diversa e está, hodiernamente, vinculada às necessidades humanas essenciais por pluralidades de interações das formas, em face da existência de novas forças sociais que buscam materializar seus interesses básicos de vida, como a necessidade de alimentação, a luta pela não exclusão através da boa educação. (WOLKMER, 2003, p.96) 
Para Bonavides (2014, p. 291) ainda baseado na obra citada de Francesco Nitti (1933, p.41-43), os gregos consideravam democracia aquelas formas de governo que garantissem a todos os cidadãos os princípios da isonomia, da isotimia e da isagoria, e fizessem da liberdade e da sua observância a base de toda sociedade política. Assim as reformas implementadas por Clístenes, tinham a isonomia como a igualdade de todos perante a lei, com iguais direitos sem distinção de grau, classe ou riqueza, conferindo o mesmo tratamento perante a ordem jurídica. Com a isotimia, abolia-se na organização democrática da Grécia, os títulos ou funções hereditárias, permitindo a todos os cidadãos as mesmas oportunidades ao livre acesso ao exercício das funções públicas, com a rotatividade e escolha para o cargo através de eleição ou sorteio. Neste mesmo condão, considerou a isegoria o principio essencial da democracia antiga, pois trata-se do direito `de palavra, igualdade do direito de manifestação na eclesia, a assembléia popular dos cidadãos, no largo cívico que era o Ágora, onde se discutiam publicamente os assuntos da polis.

Segundo Zvirblis (2006, p. 51-52), embora não se possa conceituar a democracia, considerando a inexistência de democracia acabada por não haver um conceito absoluto.

Jean Jacques Rousseau (1966, p.84), na obra Contrato Social, faz a apologia da democracia perfeita, pois entende que a soberania não pode ser dividida.

Para Bonavides (2014, p. 293), da concepção de democracia direta da Grécia, na qual a liberdade política expirava para o homem grego desde o momento em que ele, cidadão livre da sociedade, criava a lei, com a intervenção de sua vontade, e a maneira quase de um escravo se sujeitava a regra jurídica estabelecida, passamos à concepção de democracia indireta, a dos tempos modernos, caracterizada pela presença do sistema representativo.

Para Zvirblis (2006, p. 52), na atualidade dada a complexidade da vida moderna, não obstante o Estado Democrático ser aquele em que o próprio povo governa, há uma dificuldade para que o povo externe sua vontade diretamente, sendo a regra, nos dias atuais, os colégios eleitorais, prevalecendo a democracia representativa.

Para vários autores inclusive Zvirblis (2006, p. 54), citando Bonavides, no qual justifica que a democracia representativa decorre de razões práticas, pois seria impossível, tal como ocorria no Estado-cidade da antiga Grécia, convocar em praça pública, uma multidão de 
cidadãos para feitura de leis. Assim para manter a democracia com base na vontade popular, no Estado moderno foi um governo democrático de bases representativas.

\section{O CONCEITO DE DEMOCRACIA NA MODERNIDADE}

Bonavides (2014, p. 293), busca em Montesquieu pela sua atribuição a valoração da faculdade seletiva do povo e sua incapacidade de autogovernar-se para justificar a representação como técnica de organização do Estado democrático moderno.

Para o autor há duas razões de ordem prática, sendo a primeira que o antigo Estado cidade se transformou em Estado nação, cuja característica de larga base territorial sob a égide de um principio politico unificador que impõe a supremacia sobre as instituições sociais, tornando-se inviável conhecer e captar a vontade de todos os cidadãos.

A segunda consiste que o homem da democracia grega, era integralmente politico diferente do homem do Estado moderno é apenas acessoriamente político, mesmo nas democracias tidas mais aprimoradas, onde todo um sistema de garantias jurídicas e sociais fazem como efetiva e válida a sua condição de sujeito e não objeto da organização política.

Neste diapasão, na visão do autor, só há uma saída, solução do poder consentido, dentro do Estado moderno: um governo democrático de bases representativas.

Ainda considera Bonavides (2014, p. 294), analisando Rousseau que criticando a democracia indireta ou representativa, onde o homem da democracia moderna só é livre no momento que vai as urnas depositar seu voto. Para os opositores do filósofo contratualista, não há como fugir da representação, pois do contrário não haveria nenhum governo apoiado no consentimento, tomando por conta a complexidade social, a extensão e a densidade demográfica do Estado moderno, fatores estes que embaraçam irremediavelmente o exercício da democracia.

Neste mesmo sentido Zvirblis (2006,p. 55), afirma que na democracia representativa procura-se conciliar a representatividade com a democracia direta, denominada de semidireta, porque ao lado da representatividade admite-se esporadicamente a intervenção direta do povo em certas deliberações dos governantes.

Bonavides (2014, p. 296) acrescenta que à participação politica tem-se certa participação jurídica, isto é, ao povo se reconhece, para determinadas matérias, esfera de 
competência em que diretamente, observando formas prescritas na ordem normativa, cumpre atos cuja validez ficam assim sujeita ao seu indispensável concurso.

Para Silva (2016, p. 139), é no regime de democracia representativa que se desenvolvem a cidadania e as questões de representatividade, que tende a fortalecer-se no regime de democracia participativa.

Ressalta que é uma temática que merece reflexão critica. Pois, se toda democracia importa na participação do povo no processo do poder, nem toda democracia é participativa, no sentido contemporâneo da expressão.

Para Zvirblis (2006, p. 62), se a democracia é um bem da soberania popular, a participação dos cidadãos é bem sua marca eminente. A democracia exprime uma concepção de transformação que vem dos cidadãos, que devem ser guardiões desse movimento. A democracia participativa e a democracia representativa devem coexistir complementando-se, partindo da democracia indireta com a participação direta, constituindo-se a democracia semidireta, com os institutos da iniciativa popular, do referendo, do plebiscito e do recall, sendo que este instituto não é adotado na Constituição Brasileira.

Zvirblis (2006, p. 70) assevera que o recall "se constitui na revogação do mandato. É a retirada do poder de alguém que tenha sido eleito para uma função pública”.

Dessa forma, o recall é um instrumento de participação semi-direta cujo instituto implantado nos Estados Unidos, basicamente nos Estados de Oregon e Califórnia, onde determinado número de eleitores, não satisfeitos com a conduta de seu representante no poder, determina sua remoção do cargo.

Para Bonavides (2008, p. 93), a lição conclusiva destas reflexões se resume desse modo em fazer a paz axioma da democracia, designadamente a democracia participativa, com seus instrumentos, com sua teoria, com seus valores de igualdade e justiça social, já inscritos por direito positivo pelos legisladores constituintes que promulgaram no Brasil, em 1988, a Carta republicana em vigor.

Para o mesmo autor (2008, p. 82) destaca que a importância de reconhecimento jurídico do direito à paz e sua íntima integração a compreensão de democracia. Sendo a paz como um direito fundamental de quinta geração que legitima o estabelecimento da ordem, da liberdade e do bem comum na convivência dos povos.

Para Erlene Maria Coelho Avelino (2013, p.6) a democracia representativa como sinônimo da realização de eleições periódicas e livres para o governo resulta em decisões 
políticas tomadas por uma minoria, algo distante da concepção normativa que a palavra carrega uma forma de organização política baseada na igualdade potencial de influência de todos os cidadãos.

Constata-se que predomina a concepção hegemônica de democracia, o modelo liberal representativo com a ausência do governo do povo, por esta tratar-se de uma utopia.

Luis Felipe Miguel (2002, p. 485), credita parte da distância entre as duas faces da democracia aos regimes contemporâneos compreendidos a partir de pressupostos sobre a natureza humana sobre a organização das sociedades emprestados da teoria das elites, uma corrente teórica que nasceu para afirmar a impossibilidade das democracias.

O modelo liberal considera que não se possa eliminar a distância entre sociedade e Estado, mas que se deva prevalecer uma ligação entre ambos mediante o processo democrático.

Para Avelino (2013, p. 8), citando que para Max Weber a democracia deve ser concebida como um mecanismo institucional para eliminar os mais débeis e estabelecer os mais competentes na luta competitiva pelos votos e poder.

Segundo a mesma Autora (2013, p. 8), ele estava preocupado em encontrar "vias para garantir um equilíbrio efetivo entre a autoridade política, uma liderança qualificada, uma administração eficiente e um grau de responsabilidade política"

Avelino (2013, p. 8) busca em Schumpeter (1984), que sintetiza seu conceito de democracia concorrencial o qual considera que o método democrático é um sistema institucional, para a tomada de decisões políticas, no qual o indivíduo adquire o poder de decidir mediante uma luta competitiva pelos votos do eleitor.

Na sua visão elitista, a democracia corresponde em um "método para promover o bem comum através da tomada de decisões pelo próprio povo com a intermediação de seus representantes", pois não há um bem comum, uma vez que para diferentes grupos e indivíduos, o bem comum terá significado diversos. Ainda nesta avaliação da natureza humana onde impera a irracionalidade do ser humano quando se há a disputa das questões públicas.

Ainda analisando Schumpeter (1984, p. 322) que não fala de representação política, mas de liderança, pois os governantes não precisariam prestar contas de seus atos aos cidadãos comuns, segundo o qual "A vontade do povo é o produto e não a força motriz do processo político". 
Neste sentido desenvolve um conceito de democracia enquanto método que elimina o ideal de soberania popular, isto sem falar em qualquer possibilidade de controle social.

Avelino (2013, p. 9-10) comparando com Dahl (2001) o qual elaborou uma teoria democrática na qual uma multiplicidade de "centros de poder" complementa a existência das minorias concorrente, onde a invenção da representação permitiu a vigência da democracia em sociedades complexas e heterogêneas, centrado nas eleições como método democrático.

Para Avelino (2013, p. 10), a teoria liberal representativa se resume em duas idéias centrais: a de restrição da participação política dos cidadãos ao voto eleitoral periódico para a escolha de seus representantes e a de que a base para o processo de tomada de decisões ocorre através de preferências individuais dadas.

O elitismo democrático conseguiu responder as perguntas de formas mais contundente por conceber o Estado como um aparato administrativo, a sociedade dentro de uma lógica de mercado e a política como uma garantia dos interesses privados

Segundo Luciana Rosa Marques (2008, p. 58), da teoria democrática deveria emergir com base nos critérios de participação política que não se restringe apenas ao ato de votar, realizando uma revisão na politização global da prática social, criando novas oportunidades para o exercício de novas formas de democracia e de cidadania, transformando relações de poder em relações de autoridade partilhada, nos diferentes espaços de interação social, pressupondo, assim, novos critérios democráticos para avaliar as diferentes formas de participação política e, com isso, valorizar a idéia da igualdade sem inalterabilidade, da diferença, da autonomia e da solidariedade.

Avelino (2013, p. 13), se baseia em Carole Pateman através de sua obra "Participation and democratic theory" (1992) que contrapõe à ideia de que a democracia deveria se restringir à mera participação eleitoral dos representados, considerando como onda elitista de democracia que se desenvolveu no século XX.

Para Avelino (2013, p. 13), o argumento de Pateman questiona com base na crítica aos teóricos da democracia liberal, especialmente Schumpeter, que compreendeu as "teorias clássicas da democracia" de forma equivocada, pois essa interpretação das teorias participativas clássicas, que não passaria de um mito, e o argumento de que as propostas que estas defendiam não poderiam ser utilizadas nas sociedades contemporâneas geraram uma percepção errônea sobre a participação política. Desse modo, ela irá reconstruir uma teoria participativa da democracia através da releitura Jean Jacques Rousseau, John Stuart Mill e G.D. H. Cole. 
Marques (2008, p. 64), discorre que a democracia radical e plural visa expandir sua esfera de aplicabilidade a novas relações sociais, não se limitando, assim, à forma de governo adotada pelo Estado, objetivando, portanto, criar um novo tipo de articulação entre os elementos da tradição democrática liberal, em que os direitos não se enquadram numa perspectiva individualista, mas democrática, criando uma nova hegemonia, que é resultante de um maior número de lutas democráticas, e, conseqüentemente, a multiplicação dos espaços políticos na sociedade.

Ainda para Marques (2008, p. 70) interpretando Santos (2001), a democracia participativa, alternativa que se coloca no campo das teorias não-hegemônicas e espaço da emancipação social pela transformação das relações de poder pelas relações de autoridade compartilhada ${ }_{2}$ onde se tem experimentado inovações que parecem bem sucedidas, as quais possibilitam a instauração de uma nova determinação política baseada na criatividade dos atores sociais.

As mudanças mais significativas no formato democrático têm suas origens em movimentos sociais que questionaram práticas sociais excludentes, por meio de ações que geraram novas formas de controle do governo pelos cidadãos, surgindo a partir de mudanças em práticas societárias introduzidas pelos atores sociais e resgatando tradições democráticas locais, ignoradas pelas formas de democracia representativas hegemônicas.

Para Marques (2008, p. 71), os diferentes formatos de democratização, construídos pela participação ampliada de atores sociais em processos de tomada de decisões, alargam a possibilidade de procedimentos inovadores, que se tornam objeto de intensa disputa política por, em geral, incluírem temáticas ignoradas pelo sistema político, promoverem a redefinição de identidades e vínculos e o aumento da participação, especialmente no nível local.

Assim a autora (2008, p. 71) a partir de Santos (2002), defende três teses para o fortalecimento da democracia participativa. A primeira é o reconhecimento de que não existe um único formato democrático, o que é apontado pelo multiculturalismo e pelas experiências de participação no sentido da ampliação da deliberação pública. Assim, o primeiro elemento da democracia participativa seria o aprofundamento dos casos em que o sistema político abre mão de suas prerrogativas decisórias em favor de instâncias coletivas de decisão.

A segunda é a passagem do contra-hegemônico do plano local para o global, como elemento essencial ao fortalecimento da democracia participativa. A articulação global/local 
torna possível a aprendizagem contínua, considerada requisito fundamental do êxito das práticas democráticas animadas pela possibilidade da democracia de alta intensidade.

A terceira tese advoga a ampliação do experimentalismo democrático, pois a pluralização cultural, racial e distributiva da democracia requer que se multipliquem experimentos nessas direções.

As experiências de democracia participativa resgatam a dimensão pública e cidadã da política, na medida em que mobilizam setores sociais interessados em determinadas políticas públicas, bem como apontam formas alternativas de organização do sistema político, realizando, assim, uma nova politização global da vida coletiva.

\section{CIDADANIA E DEMOCRACIA NA CONTEMPORANEIDADE}

Para Zvirblis (2006, p. 169) a cidadania se constitui em liberdade política, no exercício dos direitos, quer no aspecto de liberdade negativa, liberdade de ação, quer no aspecto de liberdade positiva, de vontade conforme bem apontado por Norberto Bobbio (1996, p.49). Ele lembra ainda, que Hannah Arendt conceituou a cidadania como o estado de pertencer a uma comunidade capaz de lutar pelos direitos de seus integrantes como o "direito de ter direitos".

Portanto para o autor (2006, p. 169) ,ser cidadão é ter direito à vida, à liberdade, à propriedade, à igualdade perante a lei; é, em resumo, ter direitos civis, bem como participar do destino da sociedade, votar, ser votado e ter direitos políticos.

Destaca ainda, que cidadania é o direito de participar da vida política do Brasil e se constitui em um dos fundamentos do Estado Democrático de Direito conforme descrito na Constituição da República Federativa do Brasil (1988), em artigo $1^{\circ}$, inciso II.. Mas, para isso, deve ser adquirida e pelas condições fixadas pelo próprio Estado, como pode decorrer do nascimento ou de determinadas condições e pressupostos estabelecidos pelo próprio Estado.

Ainda para Zvirblis (2006, p. 170), a condição de cidadania traz como consequiência direitos e deveres que acompanham o indivíduo mesmo que se afaste de seu Estado.

Portanto descreve o autor (2006, p. 170), a cidadania ativa não pode deixar de preencher os requisitos exigidos pelo Estado, pois, caso contrário, o indivíduo poderá perdê-la, sendo esta perda de suma gravidade, mormente se o indivíduo não tiver condições de ser cidadão de outro Estado, ficando impossibilitado de conviver em associações. Desta maneira, a perda só pode ocorrer em casos em que for absolutamente necessária.

Rev. de Teorias da Democracia e Direitos Políticos | e-ISSN: 2525-9660 | Maranhão | v. 3 | n. 2 | p. 89 - 110 | Jul/Dez. 2017. 
Para Dalmo de Abreu Dallari (2004, p.14), "a cidadania expressa um conjunto de direitos que dá à pessoa a possibilidade de participar ativamente da vida e do governo de seu povo". Não obstante as dificuldades de se conceituar o termo cidadania, clássico é a definição do sociólogo britânico Theodore Humprhey Marshall, que, analisando a evolução histórica da cidadania no Reino Unido, desenvolveu a distinção entre as três dimensões da cidadania: civil, política e social, de forma que seria considerado cidadão àquele titular das três categorias de direitos correspondentes.

A cidadania não se restringe a delegação ao Estado da tarefa de promover a justiça social, concepção eivada nas idéias de assistencialismo e paternalismo, mas compreende uma postura ativa dos cidadãos, uma vez que são eles que possuem as condições para promover a transformação de sua realidade (BITTAR, 2004, p. 11).

Segundo as autoras Elba Pereira Domingos e Rosângela Palhano Ramalho (2012, p. 5), o controle social é a participação na gestão pública que garante aos cidadãos espaços para influir nas políticas públicas, além de possibilitar o acompanhamento, avaliação e a fiscalização das instituições públicas e organizações não governamentais, visando assegurar os interesses da sociedade. Elas destacam que o controle social é um dos instrumentos de efetivação da democracia participativa, que por consequêencia faz jus a aplicação da quinta geração dos direitos humanos.

Assim segundo as mesmas autoras (2012, p. 5), a participação contínua da sociedade na gestão pública não só configura a democracia participativa como permite que os cidadãos não só atuem na formulação das políticas públicas, como também, verifiquem o real atendimento as necessidades da população e fiscalizem de forma permanente a aplicação dos recursos públicos.

Com essa atitude de participação, acompanhamento e fiscalização, o cidadão exerce o controle social, interferindo no direcionamento das políticas públicas, exigindo e promovendo a transparência e o uso adequado dos recursos públicos. Esse exercício ocorre em espaços públicos de articulação entre governo e sociedade, constituindo importantes mecanismos de fortalecimento da cidadania, conforme se extrai do documento "Capacitação para controle social nos municípios “(BRASIL, 2011, p. 30). 
Para Maria das Graças Ruas (2009, p. 21), é importante desenvolver a compreensão de que as políticas públicas são resultantes da atividade política e que esta consiste na resolução pacífica de conflitos, processo essencial à preservação da vida em sociedade.

Segundo Helena da Motta Salles (2010, p. 79), a participação social, quando efetiva, é capaz de elevar a governabilidade, pois tende a impactar a máquina administrativa promovendo maior transparência, agilidade e flexibilidade, garantindo a adaptabilidade de longo prazo das políticas públicas.

Ainda constata a mesma autora (2010, p. 79), a reunião de representantes do governo e da sociedade civil, inclusive quando há um processo amplo de mobilização popular através dos movimentos sociais em um espaço legítimo de discussão. Cita como exemplo, os espaços contidos nos Conselhos Gestores, Conselhos Temáticos, Orçamento Participativo, Fóruns, dentre outros instrumentos que tem por finalidade dar maior transparência à gestão, além de promover um aprendizado democrático entre as partes, que se traduz em benefícios para ambos.

A Constituição da República Federativa do Brasil (1988) apresenta, com efeito, uma nova configuração da gestão das políticas públicas, instituindo novos mecanismos nos processos de tomada de decisões, o que faz emergir um regime de ação pública descentralizada, no qual são criadas formas inovadoras de interação entre governo e sociedade, através de canais e estratégias de participação social, como se dá com os Conselhos Gestores (SANTOS JÚNIOR, 2001, p. 228).

Para Salles (2010, p. 43) baseado na obra de Leonardo Avritzer (2007), entende que a partir da institucionalização de diversas sugestões de medidas surgidas no processo de redemocratização, emergiram no país formas de representação não eleitoral, ou representação por afinidade, categoria na qual se incluem os Conselhos Municipais.

Da mesma autora (2010, p. 47), os conselhos responsáveis pela democratização das políticas sociais contribuíram para o resgate da "dívida social", um dos compromissos da redemocratização. Entre elas destacamos: a da saúde (Lei Orgânica da Saúde), a da assistência social (Lei Orgânica da Assistência Social), a da proteção à criança e ao adolescente (Estatuto da Criança e do Adolescente) e, as mais recentes, a da política urbana (Estatuto da Cidade) e da Cultura (Sistema Nacional de Cultura).

Há o entendimento que tais conselhos funcionam no Brasil como instrumentos democráticos de participação popular, com a aparência do desenvolvimento de "uma nova cultura vinculada tanto à dimensão dos direitos sociais inscritos na Constituição de 1988 como 
à participação de uma pluralidade de atores sociais com presença na cena pública, na perspectiva de uma democracia participativa." (SANTOS JÚNIOR, 2001, p. 1).

Para Dallari (2004), os objetivos econômicos do neoliberalismo brasileiro, presentes na carta magna como por exemplo a garantia do lucro ilimitado e a integralidade do direito de herança, privilegiam os interesses privados em detrimento dos interesses públicos, e por tal razão, o exercício pleno da cidadania de algumas categorias esbarra sempre na indiferença dos setores econômicos dominante.

Assim, para Marques (2008, p. 62), os novos movimentos sociais apresentam um potencial de construção de uma sociedade mais livre, democrática e igualitária, cuja efetivação dependerá das formas de articulação definidas entre as exigências democráticas.

Portanto pode-se extrair que os movimentos sociais têm sido ao longo da história elementos fundamentais para as transformações com a aquisição de direitos civis, a concretização de modelos que permitam a implementação de instrumentos de gestão democrática possibilitando a articulação dos segmentos da sociedade civil, em especial dos setores populares, inclusive os considerados como vulneráveis.

\section{DEMOCRACIA DELIBERATIVA E PARTICIPATIVA}

Para Marques (2008, p. 64), a democracia radical e plural visa expandir sua esfera de aplicabilidade a novas relações sociais, não se limitando, assim, à forma de governo adotada pelo Estado, objetivando, portanto, criar um novo tipo de articulação entre os elementos da tradição democrática liberal, em que os direitos não se enquadram numa perspectiva individualista, mas democrática, criando uma nova hegemonia, que é resultante de um maior número de lutas democráticas, e, consequentemente, a multiplicação dos espaços políticos na sociedade.

Assim continua a autora (2008, p. 65), uma hegemonia de valores democráticos se expressa na multiplicação de práticas democráticas, que se institucionalizam em diversas formas de relações sociais. A materialização do projeto de democracia radical poderia proporcionar, assim, a experiência da vivência democrática na sociedade atual, que se basearia 
na articulação entre várias lutas democráticas, resultando na criação de novas posições de sujeitos.

Discorre que as mudanças mais significativas no formato democrático têm suas origens em movimentos sociais que questionaram práticas sociais excludentes, por meio de ações que geraram novas formas de controle do governo pelos cidadãos, surgindo a partir de mudanças em práticas societárias introduzidas pelos atores sociais e resgatando tradições democráticas locais, ignoradas pelas formas de democracia representativas hegemônicas.

Marques (2008, p. 71) baseando-se em Boaventura de Sousa Santos (2002), o qual define a democracia participativa constituiria um dos grandes campos sociais e políticos, nos quais, no início do novo século, a emancipação social está sendo reinventada a partir do processo de redemocratização dos países do Sul, nos quais houve um processo de redefinição de seu significado cultural e da gramática social, possibilitando a disputa pelo significado de práticas políticas e a incorporação de novos atores sociais e novos temas à democracia.

Assim a autora conceitua que os diferentes formatos de democratização, construídos pela participação ampliada de atores sociais em processos de tomada de decisões, alargam a possibilidade de procedimentos inovadores, que se tornam objeto de intensa disputa política por, em geral, incluírem temáticas ignoradas pelo sistema político, promoverem a redefinição de identidades e vínculos e o aumento da participação, especialmente no nível local. Portanto ela discorre que a prática da participação busca aprofundar e intensificar a democracia, quer reivindicando a legitimidade da democracia participativa, quer pressionando as instituições democráticas representativas para torna-las mais inclusivas, ou ainda buscando formas de complementaridade entre democracia participativa e representativa.

Neste sentido, Avritzer (2000, p. 25) examina a questão da deliberação na teoria democrática mediante o confronto entre dois modelos de deliberação: o decisionista e o argumentativo. Alguns autores têm utilizado o termo com o significado de um processo no qual um ou mais agentes avaliam as razões envolvidas em uma determinada questão (Habermas, 1994; Cohen, 1989); outros autores utilizam o termo tendo em vista o momento no qual o processo de tomada de decisão ocorre (Rousseau, 1968; Schumpeter,1942; Rawls,1971).

$\mathrm{Na}$ análise do autor, alguns autores clássicos como Jean Jacques Rousseau privilegiaram o aspecto decisório, no interior do processo deliberativo, ao identificar o processo de formação da vontade geral com o processo de aferição da vontade da maioria, propõe uma concepção de democracia baseada nos seguintes elementos: a decisão como o elemento central do processo 
deliberativo; a idéia de que, uma vez aferida a vontade da maioria, a posição perdedora nada mais representa do que um erro.

Avritzer (2000, p. 26) descreve que autores como Touraine, Habermas, Cohen, Melucci e Bohman, que propuseram teorias dos movimentos sociais ou teorias da esfera pública, chamaram a atenção para a centralidade do momento argumentativo, momento esse entendido como um "...intercâmbio de razões feito em público" (Cohen, 1997:73), como autores que trabalham com a questão da identidade (Melucci, 1996; Young, 1996) também chamaram a atenção para a centralidade do processo argumentativo no momento do reconhecimento da validade de uma identidade alternativa.

Assim, um conjunto de experiências administrativas onde vários autores (Santos, 1998; Abers,1998; Avritzer, 2000; Fung, 2000) tem colocado em cheque os principais elementos de uma concepção decisionística de deliberação, em particular a idéia defendida a partir de Weber (1919) de que as formas complexas de administração podem prescindir de elementos participativos e argumentativos.

Para Avritzer (2000, p. 26), Max Weber foi o teórico social que formulou os elementos de uma concepção decisionística de deliberação: o primeiro desses elementos seria o ceticismo em relação a debates envolvendo tradições culturais distintas cujas divergências extrapolavam o Estado nacional; o segundo seria a percepção de que a complexidade administrativa seria contraditória tanto com a participação quanto com a argumentação. Para Weber, "as esferas de valor do mundo estão em conflito irreconciliável entre si." (WEBER, 1946, p.176), onde as divergências culturais só poderiam ser solucionadas cientificamente, onde entende que a ciência não se presta a esse papel tem profundas implicações políticas. Caberá a Joseph Schumpeter fornecer a resposta definitiva do elitismo democrático a essa questão.

Segundo Avritzer (2000, p. 28), Weber introduziu um segundo campo de questionamentos com repercussão sobre o conceito de deliberação, ao questionar os fundamentos da soberania popular, em especial, sua utilidade no campo da administração. Ainda em polêmica implícita com Marx, irá utilizar o conceito de separação entre trabalhadores e meios de produção para propor um conceito de complexidade administrativa no qual a participação popular somente poderia se constituir em obstáculo.

Portanto, a argumentação ou a participação seriam completamente contraproducentes, no sentido de produzirem resultados sejam mais racionais ou mais eficientes. 
O ceticismo em relação às formas argumentativas de deliberação, que tem sua origem em Weber, onde através de Schumpeter considerado o autor de transição onde dois elementos do decisionismo deliberativo serão reforçados pelas formulações: a rejeição de formas públicas de discussão e argumentação e a identificação das práticas decisórias com o processo de escolha de governantes. Ainda irá avaliar os potenciais argumentativos da democracia no marco de uma análise da sociedade de massas.

Avritzer (2000, p. 30) descreve que Anthony Downs, apesar de menos seduzido pela teoria da sociedade de massa do que Schumpeter, irá fornecer um formato final à teoria ao supor que os indivíduos nas sociedades democráticas possuem duas qualidades que os definiriam como racionais: a capacidade de formar um ranking de preferências e de relacionar as preferências por eles detidas com as propostas políticas feitas na sociedade pelas elites políticas (Downs, 1956).

Avritzer (2000, p. 31) afirma que a teoria democrática possui três elementos decisionísticos e anti-argumentativos: 1) O primeiro consiste que as diferenças culturais não podem ser resolvidas por meio da argumentação. Assim a única forma de se fazer política democrática seria deixando tais diferenças de lado. 2) O segundo está relacionado à defesa de uma inter-relação estreita entre administração não participativa e preservação da complexidade. Assim a redução das demandas e a capacidade da burocracia de segui-las racionalmente que determina a eficiência. 3) O terceiro é a idéia de que o processo eleitoral consiste na aferição de preferências individuais pré-formadas.

Para Avritzer (2000, p. 32) John Rawls é o um autor de transição entre uma concepção decisionística de deliberação e uma concepção argumentativa, na medida em que opera com um consenso decisionístico e, em outras, ele supõe que as diferenças culturais são parte de uma condição de pluralismo que supõe a argumentação e a deliberação, que consiste em reconhecer as diferenças entre os indivíduos na medida em que o autor reconhece que eles "discordam sobre os termos básicos da sua associação" (Rawls, 1971, p. 5) e, ao mesmo tempo, supor que tais diferenças podem ser suspensas no momento da discussão na posição original acerca de uma concepção de justiça. Porém não encontramos em Rawls, o que seria uma teorização dos fóruns argumentativos nos quais a deliberação argumentativa teria lugar em uma sociedade democrática.

Para Cláudia Feres Faria (2000, p. 48), Jürgen Habermas, ao elaborar o conceito de democracia discursiva deliberativa, está preocupado com o modo que os cidadãos fundamentam 
racionalmente as regras do jogo democrático. Para a teoria democrática "convencional" a fundamentação do governo democrático se dá por meio do voto. Dado que esse instrumento não é suficiente para legitimar a democracia, a teoria do discurso propõe um "procedimento ideal para a deliberação e tomada de decisão" que avançaria, segundo esse autor, em termos da fundamentação e legitimação das regras democráticas. Tal procedimento democrático, "ao conjugar considerações pragmáticas, compromissos, discursos de auto compreensão e de justiça, fundamenta o pressuposto de que resultados racionais e justos serão obtidos por meio de um fluxo de informação relevante cujo o emprego não deve ser obstruído".

Faria (2000, p. 48), ao analisar a teoria do discurso, "a razão prática (base desse procedimento democrático) passa dos direitos humanos universais ou da substância ética concreta de uma determinada comunidade para as regras do discurso e para as formas de argumentação. Tais regras extraem seu conteúdo normativo das bases de validade da ação orientada pelo entendimento e, em última instância, da estrutura de comunicação linguística e da ordem insubstituível da socialização comunicativa" (Habermas, 1997, v. II, p. 19).

Para Avritzer (2000, p. 40) a concepção habermasiana de discurso racional resgata a dimensão argumentativa do discurso na medida em que ela rejeita dois pressupostos: o pressuposto de que a vontade da maioria, ou a homogeneidade da comunidade ética pode se autolegitimar na política moderna e o pressuposto de que é possível barganhar em torno de interesses pré-estabelecidos. A essas duas concepções, Habermas opõe uma terceira, que é baseada na idéia de deliberação argumentativa.

Faria (2000, p. 49), a operacionalização desse procedimento ideal de deliberação e tomada de decisão, ou seja, das políticas deliberativas, depende, segundo a teoria do discurso, da institucionalização dos procedimentos e das condições de comunicação, bem como da interrelação de processos deliberativos institucionalizados com as opiniões públicas informalmente constituídas (Habermas, 2010, v. II, p. 21).

Ainda Faria (2000, p. 53), comenta que a democracia deliberativa proposta por Habermas utiliza uma estratégia dual, onde se apresentam fóruns institucionais e extra institucionais que se apoiam nos sujeitos da sociedade civil, bem como em outros atores políticos tais como os sindicatos, os partidos e os grupos de interesses.

Neste sentido Marques (2008, p. 67), através da análise de Boaventura de Sousa Santos, o qual considera que a democracia assumiu um lugar central no campo político no século XX, 
no qual foi objeto de disputa entre regulação e emancipação. Um dos processos que levou à quebra do equilíbrio entre emancipação e regulação em favor da segunda foi a redução da política a uma prática social setorial e especializada, com uma rígida regulação da participação. Os espaços de poder, que têm formas de dominação diferenciada, têm também formas de resistência que se integram a uma constelação de práticas emancipatórias.

Marques (2008, p. 70) seguindo a definição de Santos (2001, p. 269), a democracia participativa, alternativa que se coloca no campo das teorias não-hegemônicas e espaço da emancipação social pela transformação das relações de poder em relações de autoridade compartilhada, tem experimentado inovações que parecem bem sucedidas, as quais possibilitam a instauração de uma nova determinação política baseada na criatividade dos atores sociais.

Portanto para Faria (2000, p. 64), a legitimidade do processo democrático deriva principalmente da participação dos cidadãos no processo de tomada de decisão. Essa participação vai além do ato de votar e é caracterizada por uma outra racionalidade complexa que não só a instrumental e a estratégica.

\section{CONCLUSÃO}

Primeiramente é necessário destacar que o exercício da cidadania está vinculado ao modelo de democracia vigente limitado pelo poder politico e o poder econômico conforme constatamos no processo de evolução histórica narrada a partir de sua história teóricoconceitual.

Ao examinarmos esta evolução da democracia podemos considerar que sempre houve o elitismo no processo representativo limitando-se a participação ao exercício do voto pela delegação ao outro da sua capacidade de decisão. Já na proposta da democracia participativa, esta deliberação é construída no processo de articulação coletiva onde as demandas são conciliadas a partir das reflexões participativas de forma isonômica.

Constata-se que a democracia ao longo dos anos passa por crises cíclicas que resultam numa flexibilização do poder político sob o poder econômico permitindo ajustes nos processos decisórios.

Pode-se tomar como referência ao modelo do sistema político vigente no País, onde o presidencialismo se torna hibrido, com o Executivo coptando o Legislativo para a gestão 
política da estrutura administrativa, culminando na crise institucional em decorrência ao descumprimento aos padrões da ética e moralidade submetendo ao poder econômico.

Em suma, o poder político não representa os segmentos populares que os vinculam a capacidade do voto com o exercício da cidadania plena, uma vez que todas políticas públicas passam a prestigiar tão somente um reduzido segmento da elite.

Na Grécia antiga, houve uma conformação da aristocracia democrática, ou mesmo a representação minoritária, onde uma pequena parcela da população era considerada cidadã, onde escravos, mulheres e estrangeiros eram excluídos da participação política e os cidadãos viviam exclusivamente dos negócios públicos.

Os elementos principais da evolução conceitual da democracia foram na democracia moderna o Estado cidade, se transforma em Estado nação e a democracia torna-se representativa. Muda a relação entre democracia e cidadania: a vontade da maioria predomina, mas elitizada. A compreensão de relações de poder passa para autoridade compartilhada. $\mathrm{O}$ cidadão, limitado ao simples exercício do voto, elege representantes, delega sua capacidade de decisão a um terceiro. Porém fica sem condições de interferência no poder político o qual passa a subordinação do poder econômico.

Na contemporaneidade desenvolvem-se, a relação conceitual entre direitos e cidadania, os conceitos de democracia participativa e deliberativa aparecem suprindo lacunas da democracia representativa. Torna-se possível, juntar a ampliação moderna da democracia à efetiva participação dos cidadãos como na antiguidade. Busca-se devolver a capacidade política articulada como processo coletivo dos cidadãos, permitindo maior controle social, seja nas ações administrativas como também no resgate da capacidade deliberativa resultando numa relação horizontal do poder político.

Portanto amplia-se os processos de capacitação, intervenção e formulação de políticas públicas desde a sua definição, elaboração, discussão, implementação, fiscalização e pós execução. Instaura-se a ampliação da democracia e da paz a partir dos valores de igualdade e justiça social, efetivando dignidade e direitos humanos.

Para que se tenha a concretização dos direitos humanos é necessário ampliar o exercício da cidadania com a ampla participação de todos os segmentos da sociedade civil valendo-se da sua representatividade efetiva de forma inclusive ao pleno exercício do controle social. 


\section{REFERÊNCIAS BIBLIOGRÁFICAS}

AVELINO, Erlene Maria Coelho. Democracia Participativa na Venezuela: contribuições e desafios para o estudo da teoria democrática - Monografia de Graduação Instituto de Relações Internacionais - Universidade de Brasília, 2013 disponível em: http://bdm.unb.br/bitstream/10483/6239/1/2013_ErleneMariaCoelhoAvelino.pdf Acesso em: 18dez.2016.

AVRITZER, Leonardo. Teoria democrática e deliberação pública. Lua Nova, São Paulo, n. 50, $\quad$ p. 25-46, $2000 . \quad$ Disponível <http://www.scielo.br/scielo.php?script=sci_arttext\&pid=S010264452000000200003\&lng=pt\&nrm=iso>. acesso em 20 maio 2017. http://dx.doi.org/10.1590/S0102-64452000000200003.

BITTAR, Eduardo C. B. Ética, educação, cidadania e direitos humanos. Manole, Barueri, 2004.

BONAVIDES, Paulo; Miranda Jorge; AGRA, Walber de Moura. Comentários à Constituição Federal de 1988. Rio de Janeiro: Editora Forense, 2009.

BONAVIDES, Paulo. Ciência Política. 21 ed. São Paulo: Malheiros, 2014.

A Quinta Geração de Direitos Fundamentais. Direitos Fundamentais e

Justiça número 3 Abril/Junho 2008, p.82-93. Disponível em: < http://www.ufjf.br/siddharta_legale/files/2014/07/Paulo-Bonavides-A-quintagera\%C3\%A7\%C3\%A3o-de-direitos-fundamentais.pdf >. Acesso em: 03 dez. 2016.

Curso de Direito Constitucional. 19. ed São Paulo: Malheiros, 2006.

Teoria Constitucional da Democracia Participativa: Por um Direito Constitucional de luta e resistência, Por uma Nova Hermenêutica, Por uma repolitização da legitimidade. São Paulo: Malheiros, 2001.

BOBBIO, Norberto. A Era dos Direitos. 11 ed. Rio de Janeiro:. Campus, 1992.

BRASIL, Constituição (1988). Constituição da República Federativa do Brasil. Brasília, DF: Senado Federal, 1988. 292 p.

. Ministério do Desenvolvimento Social e Combate a Fome. Capacitação para controle social nos municípios. Assistência social e programa bolsa família: Secretaria de avaliação e gestão da informação; Secretaria Nacional de Assistência social. 2011.

DAHL, Robert. Sobre a democracia. Tradução: Beatriz Sidou. Brasília: UNB, 2001

DALLARI, Dalmo de Abreu. Direitos humanos e cidadania. Moderna, São Paulo, 2004 
DOMINGOS, Elba Pereira e RAMALHO ,Rosângela Palhano . A Importância do Controle Interno na Gestão Pública Municipal: o caso dos Conselhos Municipais do município de Riachão/PB. Campina Grande Departamento de Economia/UFPB, ; [Brasília] : CAPES : UAB, 2012 Disponível em: http://portal.virtual.ufpb.br/bibliotecavirtual/files/a_importancia_do_controle_interno_na_gestao_pablica_municipal_o_caso_dos_c onselhos_municipais_do_municapio_de_riachaopb_1343925343.pdf Acesso em 02 jun 2016.

FARIA, Cláudia Feres. Democracia deliberativa: Habermas, Cohen e Bohman. Lua Nova [online]. 2000, n.50, pp.47-68. ISSN 0102-6445. Disponível em http://dx.doi.org/10.1590/S0102-64452000000200004. Acesso em 20maio2017.

MARQUES, Luciana Rosa. Democracia Radical e Democracia Participativa: Contribuições Teóricas À Análise Da Democracia Na Educação - Revista Educação e Sociedade. Campinas, vol. 29, n. 102, p. 55-78, jan./abr. 2008. disponível em: http://www.scielo.br/pdf/es/v29n102/a0429102.pdf acesso em 15dez.2016.

MIGUEL, Luis Felipe. A Democracia Domesticada: Bases Antidemocráticas do Pensamento Democrático Contemporâneo. DADOS - Revista de Ciências Sociais, Rio de Janeiro, Vol. 45, $\mathrm{n}^{\mathrm{o}} \quad 3, \quad 2002 \quad$ disponível em: http://www.scielo.br/pdf/dados/v45n3/a06v45n3.pdf acesso em 05dez.2016.

NITTI, Francesco. La Démocratie. Paris: Alcan, 1933.

PATEMAN, Carole. Participação e teoria democrática. São Paulo: Paz e Terra, 1992.

ROCHA, José Cláudio. A participação popular na gestão pública no Brasil. Jus Navigandi, Teresina, ano 16, n. 2886, 27 maio 2011. Disponível em: <http://jus.com.br/revista/texto/19205>. Acesso em: 30dez. 2016.

ROCHA, Roberto. A gestão descentralizada e participativa. Revista Pós Ciências Sociais. v. 1 n. 11 São Luis/MA, 2009. disponível em:

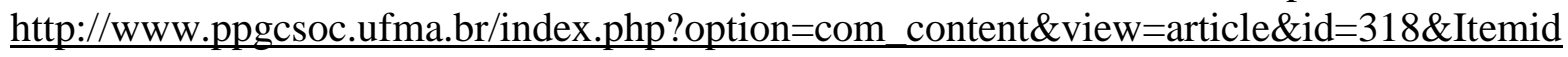
$=114$ acesso em 30 dez. 2016.

ROUSSEAU, Jean Jacques. O Contrato Social. Trad. Antonio de Pádua Danesi. São Paulo: Martins Fontes, 1966.

RUAS, Maria das Graças. Políticas Públicas, Florianópolis : Departamento de Ciências da Administração / UFSC; [Brasília] : CAPES : UAB, 2009. Disponível em:

http://ead.utfpr.edu.br/moodle/file.php/238/GPM2011/Politicas_Publicas/Documentos/Politic as_Publicas.pdf acesso em 30 dez. 2016.

SALLES, Helena da Motta. Gestão democrática e participativa - Florianópolis : Departamento de Ciências da Administração / UFSC; [Brasília] : CAPES : UAB, 2010.

SANTOS, B.S. Democratizar a democracia: os caminhos da democracia participativa. Rio de Janeiro: Civilização Brasileira, 2002.

Rev. de Teorias da Democracia e Direitos Políticos | e-ISSN: 2525-9660 | Maranhão | v. 3 | n. 2 | p. 89 - 110 | Jul/Dez. 2017. 
.A crítica da razão indolente: contra o desperdício da experiência. São Paulo: Cortez, 2001.

SANTOS JÚNIOR, O. Alves dos. Democracia e governo local: dilemas e reforma municipal no Brasil. Rio de Janeiro: Revan, 200.

SCHUMPETER, J. Capitalismo, socialismo e democracia. Tradução Sérgio Góes de Paula. Rio de Janeiro: Zahar Editores, 1984.

SILVA, José Afonso. Curso de Direito Constitucional Positivo. 39. ed. São Paulo: Malheiros, 2016.

WOLKMER, Antonio Carlos. Ideologia, Estado e Direito. 4 ed. São Paulo: RT, 2003.

ZVIRBLIS, Alberto Antonio. Democracia Participativa e Opinião Pública São Paulo: RCS, 2006. 